\title{
Communication \\ Synthesis of Au or Pt@Perovskite Nanocrystals via Interfacial Photoreduction
}

\author{
Jing Zhang ${ }^{1}$, Li Wang ${ }^{1}$, Wenwen Liu ${ }^{1}$, Mengsha Cao ${ }^{1}$, Jing Zhang ${ }^{1}$, Ningyi Yuan ${ }^{1}$, Shuai Zhang ${ }^{1, *(\mathbb{D})}$ \\ and Zhongze $\mathrm{Gu}^{2}$,*
}

1 Jiangsu Collaborative Innovation Center of Photovoltaic Science and Engineering, School of Materials Science and Engineering, Changzhou University, Changzhou 213164, China; 19085204534@smail.cczu.edu.cn (J.Z.); 18000147@smail.cczu.edu.cn (L.W.); 18000507@smail.cczu.edu.cn (W.L.); 19085204700@smail.cczu.edu.cn (M.C.); zhangjing1984@cczu.edu.cn (J.Z.); nyyuan@cczu.edu.cn (N.Y.)

2 State Key Laboratory of Bioelectronics, Southeast University, Nanjing 210096, China

* Correspondence: shuaizhang@cczu.edu.cn (S.Z.); gu@seu.edu.cn (Z.G.)

Citation: Zhang, J.; Wang, L.; Liu, W.; Cao, M.; Zhang, J.; Yuan, N.; Zhang, S.; Gu, Z. Synthesis of Au or Pt@Perovskite Nanocrystals via Interfacial Photoreduction. Catalysts 2021, 11, 174. https://doi.org/ $10.3390 /$ catal11020174

Academic Editor: Detlef

W. Bahnemann

Received: 13 December 2020

Accepted: 25 January 2021

Published: 27 January 2021

Publisher's Note: MDPI stays neutral with regard to jurisdictional claims in published maps and institutional affiliations.

Copyright: (C) 2021 by the authors. Licensee MDPI, Basel, Switzerland. This article is an open access article distributed under the terms and conditions of the Creative Commons Attribution (CC BY) license (https:/ / creativecommons.org/licenses/by/ $4.0 /)$.

\begin{abstract}
The surface modification of perovskite nanocrystals (NCs) (i.e., their decoration with noble metals) holds great promise with respect to the tailoring of their properties but has remained a challenge because perovskite NCs are extremely sensitive to water and alcohols. In this study, Au or $\mathrm{Pt} @ \mathrm{CsPbBr} 3 \mathrm{NCs}$ were successfully synthesized by photoreduction at the water/hexane interface. First, $\mathrm{Cs}_{4} \mathrm{PbBr}_{6} \mathrm{NCs}$ were synthesized through the hot-injection method. Then, $\mathrm{Cs}_{4} \mathrm{PbBr}_{6}$ was transformed into $\mathrm{CsPBr}_{3}$ and subjected to noble metal modification, both at the interface. The synthesized $\mathrm{CsPbBr}_{3} \mathrm{NCs}$ exhibited a cubic perovskite phase and had an average size of approximately $13.5 \mathrm{~nm}$. The deposited Au and Pt nanoparticles were crystalline, with a face-centered cubic lattice and average diameters of approximately 3.9 and $4.4 \mathrm{~nm}$, respectively. The noble metal modification process had almost no effect on the steady-state photoluminescence (PL) emission wavelength but affected the charge-recombination kinetics of the $\mathrm{CsPbBr}_{3} \mathrm{NCs}$. Time-resolved PL decay spectral analysis indicated that the fluorescence lifetimes of the $\mathrm{Au}$ and $\mathrm{Pt} @ \mathrm{CsPbBr} 3 \mathrm{NC}$ were shorter than those of the pure $\mathrm{CsPBr}_{3} \mathrm{NCs}$, probably owing to the quenching of the free charges because of electron transfer from the perovskite to the noble metal nanoparticles.
\end{abstract}

Keywords: perovskite nanocrystals; noble metal; interface; photoreduction

\section{Introduction}

Organic-inorganic lead halide perovskite (OIHP) materials with a general $\mathrm{ABX}_{3}$ ( $\mathrm{A}=$ organic cation, $\mathrm{B}=$ metal cation, and $\mathrm{X}=$ halide anion) formula have attracted significant attention in the field of optoelectronics because of their unique optical and semiconducting characteristics [1-3]. For instance, their use has rapidly increased the power conversion efficiency of solar cells from 3.81\% [4] to more than $25 \%$ [5] within a few years. However, owing to the instability of $\mathrm{OIHP}$, including its extreme sensitivity to oxygen and moisture, as well as its poor photo- and thermostability [6], a number of perovskite analogues have been developed. Replacing the A-site organic groups with inorganic cations to construct all-inorganic halide perovskites (IHPs) is a potential strategy for improving the stability of OIHP while maintaining its optical and electrical properties [7].

Cesium lead halide perovskite $\left(\mathrm{CsPbX}_{3}\right)$ nanocrystals (NCs), an IHP material, show great promise for use in a range of fields owing to their high photoluminescence quantum yield, narrow emission width, and tunable band gap, which covers the entire visible range [8]. They were first reported by the Kovalenko group in 2015 [9]. Since then, considerable progress has been made in the synthesis of $\mathrm{CsPbX}_{3} \mathrm{NCs}$. For instance, the hot-injection method [10,11], the solvothermal method [12], ultrasonication [13], roomtemperature precipitation [14], and chemical vapor deposition [15] have been employed to prepare $\mathrm{CsPbX}_{3} \mathrm{NCs}$ with controllable shapes and compositions. 
Although the advances made in the synthesis of $\mathrm{CsPbX}_{3} \mathrm{NC}$ s have been impressive, it is known that heterostructured NCs formed by tailoring the properties of two or more dissimilar materials usually exhibit several interesting functionalities. An example is the surface modification of $\mathrm{CsPbX}_{3} \mathrm{NCs}$ at the individual particle level $[16,17]$. However, it remains a challenge to use conventional sol-gel methods for surface modification of $\mathrm{CsPbX}_{3}$ NCs because of their water and alcohol intolerance. Recently, Hu et al. demonstrated an effective sol-gel process for modifying the surfaces of $\mathrm{CsPbX}_{3} \mathrm{NCs}$ at the interface of water and a nonpolar solvent and were able to produce $\mathrm{CsPbX}_{3} /$ metal oxide Janus NCs with improved stability [17]. Thus, interfacial synthesis is the key to preparing heterostructured NCs and is different from the other reported methods for preparing $\mathrm{CsPbX}_{3} /$ metal $[18,19]$ and $\mathrm{CsPbX}_{3} / \mathrm{SiO}_{2}$ [20] heterostructures. Inspired by their report, herein, we performed photoreduction at the water/hexane interface to produce noble metal@CsPbBr $3 \mathrm{NCs}_{3}$. First, $\mathrm{Cs}_{4} \mathrm{PbBr}_{6} \mathrm{NC}_{\text {s }}$ were synthesized through the hot-injection method. Subsequently, the $\mathrm{Cs}_{4} \mathrm{PbBr}_{6}$ was transformed into $\mathrm{CsPbBr}_{3}$ and subjected to noble metal modification, both at the interface. Owing to the localized surface plasmon resonance effect [21], high catalytic activity [22], and ease of charge separation [23] of the noble metal nanoparticles, the noble metal@ $\mathrm{CsPbX}_{3} \mathrm{NC}$ s have the potential to play an important role in photodetectors, light-emitting diodes (LEDs), solar cells, and photocatalysts.

\section{Results and Discussion}

We propose the following mechanism to explain the synthesis process (Figure 1). When the hexane suspension containing the $\mathrm{Cs}_{4} \mathrm{PbBr}_{6} \mathrm{NC}$ s comes in contact with water, the $\mathrm{Cs}_{4} \mathrm{PbBr}_{6}$ is transformed into $\mathrm{CsPbBr}_{3}$, which accompanies the stripping of $\mathrm{CsBr}$ through the hexane/water interface and removing partial hydrophobic capping ligands (i.e., oleic acid (OA) and oleylamine (OAm)) [17]. Subsequently, the noble metal precursor in contact with the interface reacts with the electrons photogenerated from $\mathrm{CsPbBr}_{3}$ (methanol was used as a sacrificial agent). According to a previous report [8], the $\mathrm{CsPbBr} 3 \mathrm{NCs}$ obtained through this water-triggered transformation process exhibit enhanced stability against moisture compared with those formed through the hot-injection method. Thus, $\mathrm{Cs}_{4} \mathrm{PbBr}_{6} \mathrm{NC}$ s were chosen to prepare the $\mathrm{Au}$ or $\mathrm{Pt}_{\mathrm{t}} @ \mathrm{CsPBr}_{3}$ NCs instead of $\mathrm{CsPbBr} 3 \mathrm{NCs}$ presynthesized by the hot-injection method.

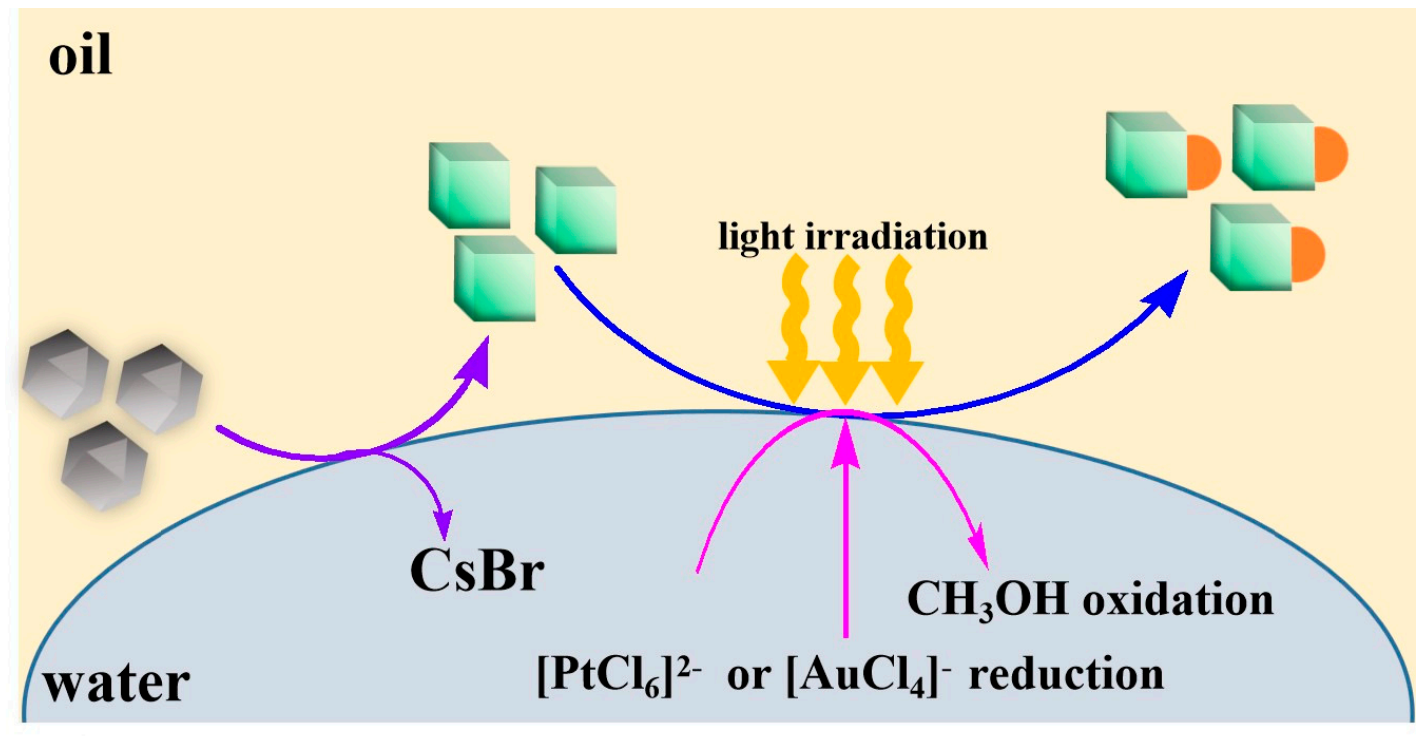

\section{$\mathrm{Cs}_{4} \mathrm{PbBr}_{6} \mathrm{NCs}$}

Figure 1. Diagram of transformation of $\mathrm{Cs}_{4} \mathrm{PbBr}_{6}$ into $\mathrm{Au}$ or $\mathrm{Pt} @ \mathrm{CsPbBr} 3$ at the water/hexane interface. NCs-nanocrystals. 
To explore the morphologies of the synthesized $\mathrm{Cs}_{4} \mathrm{PbBr}_{6}$ and $\mathrm{CsPbBr}_{3} \mathrm{NCs}$, transmission electron microscopy (TEM) imaging was performed. Figure 2a shows that the original $\mathrm{Cs}_{4} \mathrm{PbBr}_{6} \mathrm{NCs}$ are quasispherical with an average diameter of approximately $13.9 \mathrm{~nm}$. The high-resolution TEM (HRTEM) image in the inset clearly shows that the lattice spacing is $0.122 \mathrm{~nm}$ and is in good agreement with that of the (lll 101$)$ plane of rhombohedral $\mathrm{Cs}_{4} \mathrm{PbBr}_{6}$. The size distribution of the NCs was relatively narrow (Figure 2b), indicating that the NC growth process was well controlled. After the water-triggered transformation process, the NCs show a cube-like structure with an average edge length of approximately $13.5 \mathrm{~nm}$. Further, the $d$-spacing of $0.152 \mathrm{~nm}$, as measured using the HRTEM image (Figure $2 \mathrm{c}$ and its inset), could be assigned to the (1 111 ) plane of cubic $\mathrm{CsPbBr}_{3}$. The size distribution of these NCs was similar to that of the $\mathrm{Cs}_{4} \mathrm{PbBr}_{6} \mathrm{NCs}$ (Figure 2d).

(a)

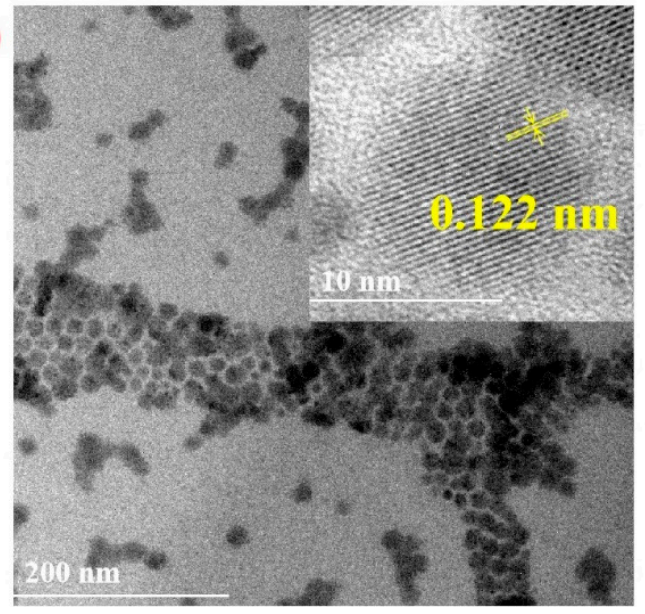

(b)

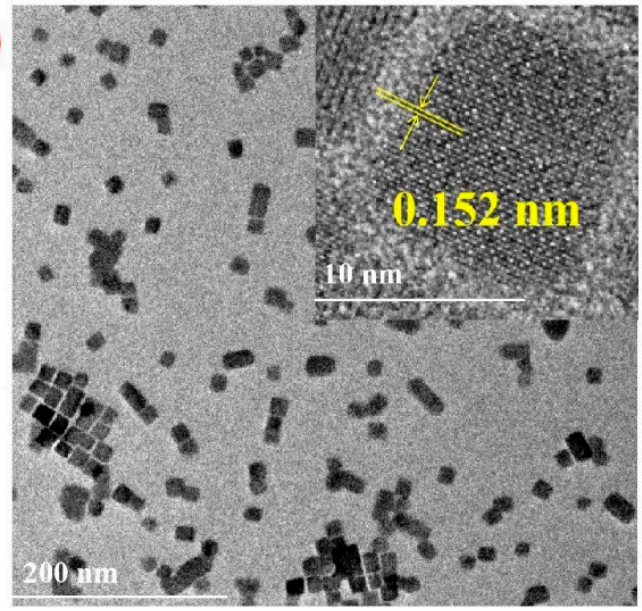

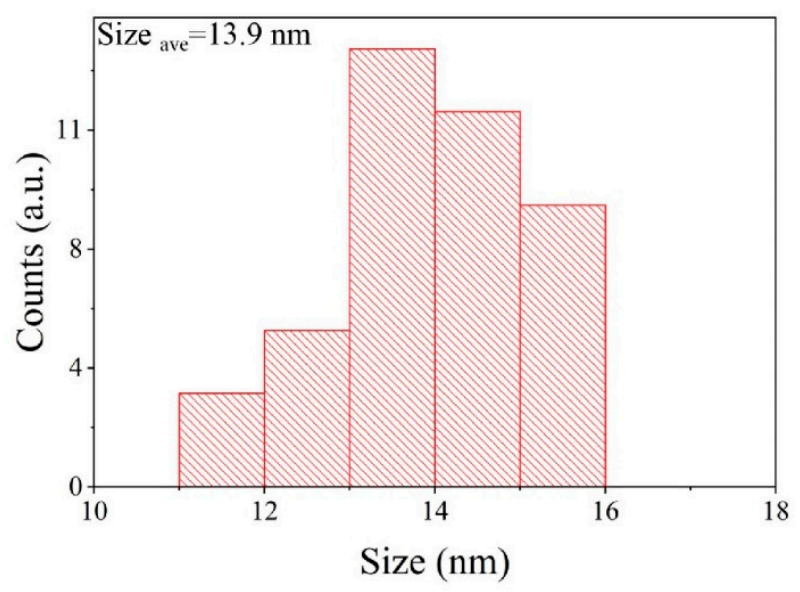

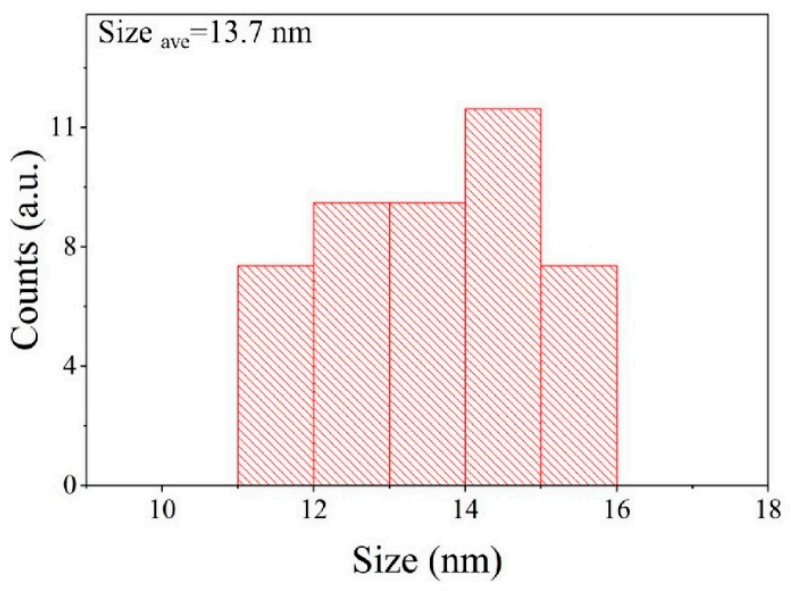

Figure 2. TEM images and size distributions of $\mathrm{Cs}_{4} \mathrm{PbBr}_{6}(\mathbf{a})$ and $\mathrm{CsPbBr}_{3} \mathrm{NCs}(\mathbf{b})$.

The transformation was also monitored through ultraviolet (UV)-visible (vis) absorption and photoluminescence (PL) measurements. As shown in Figure 3a, two sharp peaks were observed at 230 and $314 \mathrm{~nm}$ (solid black line). These could be assigned to the pristine $\mathrm{Cs}_{4} \mathrm{PbBr}_{6} \mathrm{NCs}$ [24]. The spectrum shows that the $\mathrm{Cs}_{4} \mathrm{PbBr}_{6} \mathrm{NC}$ suspension did not exhibit any distinct absorption peaks in the visible-light region, in accordance with the colorless appearance of the suspension. After the reaction with water, the sharp peak at $314 \mathrm{~nm}$ disappeared and a new absorption peak emerged at approximately $510 \mathrm{~nm}$ (solid red line), indicating the transformation of $\mathrm{Cs}_{4} \mathrm{PbBr}_{6}$ into $\mathrm{CsPbBr}_{3}$. The corresponding PL spectrum shows a sharp peak at $532 \mathrm{~nm}$, with a small full-width-at-half-maximum value. Figure $3 b$ shows the $X$-ray diffraction (XRD) pattern of the original $\mathrm{Cs}_{4} \mathrm{PbBr}_{6} \mathrm{NCs}$, as well as that of the product after the water-triggered transformation. The $\mathrm{Cs}_{4} \mathrm{PbBr}_{6} \mathrm{NC}$ s exhibit 
a rhombohedral phase, and the diffraction peaks at approximately $22.4^{\circ}, 27.8^{\circ}, 28.7^{\circ}, 29.0^{\circ}$, and $30.4^{\circ}$ correspond to the (101), (610), (230), (121), and (330) planes, respectively [17]. On the other hand, the product formed after the water treatment exhibits a pure cubic $\mathrm{CsPbBr}_{3}$ perovskite phase, and its diffraction pattern contains peaks related to the (100), (110), and (200) planes [17]. These results confirm that a change in the crystal structure from $\mathrm{Cs}_{4} \mathrm{PbBr}_{6}$ to $\mathrm{CsPBrr}_{3}$ was successfully realized at the water/hexane interface.
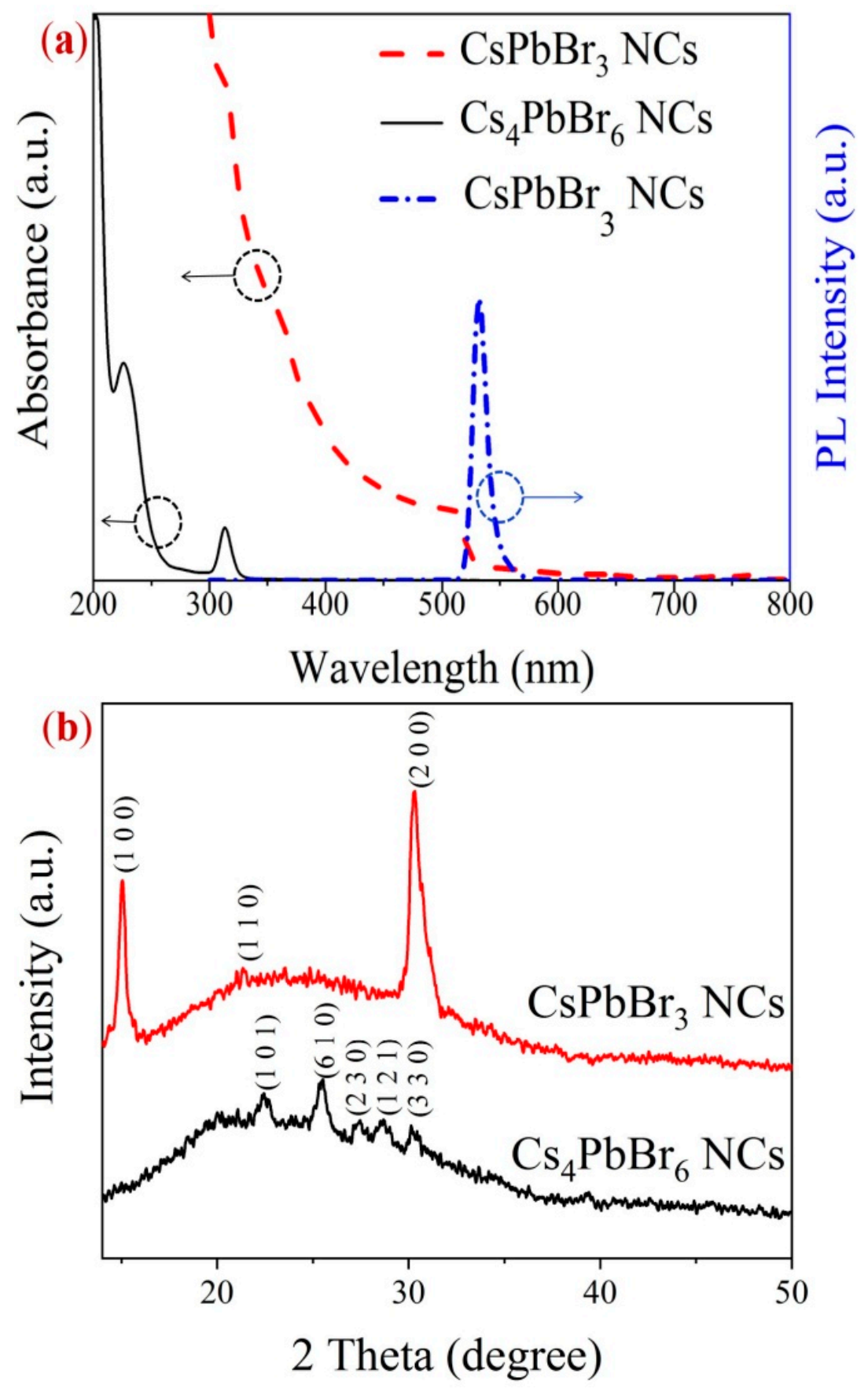

Figure 3. (a) Absorption and photoluminescence (PL) spectra and (b) X-ray diffraction (XRD) patterns of $\mathrm{Cs}_{4} \mathrm{PbBr}_{6}$ and $\mathrm{CsPbBr}_{3}$ NCs. The background of XRD patterns in (b) is shifted because of artificial translation of Y-axis.

Figure 4 shows the TEM images of the Au or Pt@CsPbBr 3 hybrid NCs prepared by reacting $\mathrm{Cs}_{4} \mathrm{PbBr}_{6} \mathrm{NCs}$ with the corresponding noble metal precursor under light 
irradiation at the water/hexane interface. These hybrid NCs were similar in shape and size to the pure $\mathrm{CsPbBr}_{3} \mathrm{NCs}$ shown in Figure 1c. Moreover, the $\mathrm{Au}$ and $\mathrm{Pt}$ nanoparticles were deposited randomly on the surfaces of the $\mathrm{CsPbBr}_{3} \mathrm{NCs}$, and their sizes were relatively small, at 3.9 and $4.4 \mathrm{~nm}$, respectively. The HRTEM images show that the formed Au and Pt nanoparticles are crystalline with $d$-spacings of 0.106 and $0.090 \mathrm{~nm}$, respectively, which correspond to the face-centered cubic (fcc) Au (400) (JCPDS Card No. 04-0784) and Pt (331) planes (JCPDS Card No. 70-2057), respectively. These results confirmed that the photoreduction reaction had been carried out successfully at the water/hexane interface. The X-ray photoelectron spectroscopy (XPS) survey scans of $\mathrm{Au} @ \mathrm{CsPbBr} 3$ and $\mathrm{Pt}_{\mathrm{C}} \mathrm{CsPbBr}$ $\mathrm{NCs}$ are presented in the left of Figure 5, in which the presence of $\mathrm{Cs}, \mathrm{Pb}, \mathrm{Br}$, and $\mathrm{Au}$ (or $\mathrm{Pt}$ ) elements is confirmed. In the high-resolution XPS spectra (the right part of Figure 5), doublet peaks containing a low energy band $\left(\mathrm{Au}_{4} \mathrm{f}_{7 / 2}\right)$ and a high energy band $\left(\mathrm{Au}_{4} \mathrm{f}_{5 / 2}\right)$ are observed at 84.0 and $87.7 \mathrm{eV}$ for $\mathrm{Au} @ \mathrm{CsPbBr} 3$, respectively, and $71.0\left(\mathrm{Pt}_{4 \mathrm{f}} / 2\right)$ and $74.3 \mathrm{eV}\left(\mathrm{Pt}_{4} \mathrm{f}_{5 / 2}\right)$ for $\mathrm{Pt} @ \mathrm{CsPbBr} 3$, which are assigned to metallic $\mathrm{Au}(0)$ or $\mathrm{Pt}(0)[25,26]$. The results demonstrate that the noble metal precursors can be effectively reduced through the interfacial photoreduction.

(a)
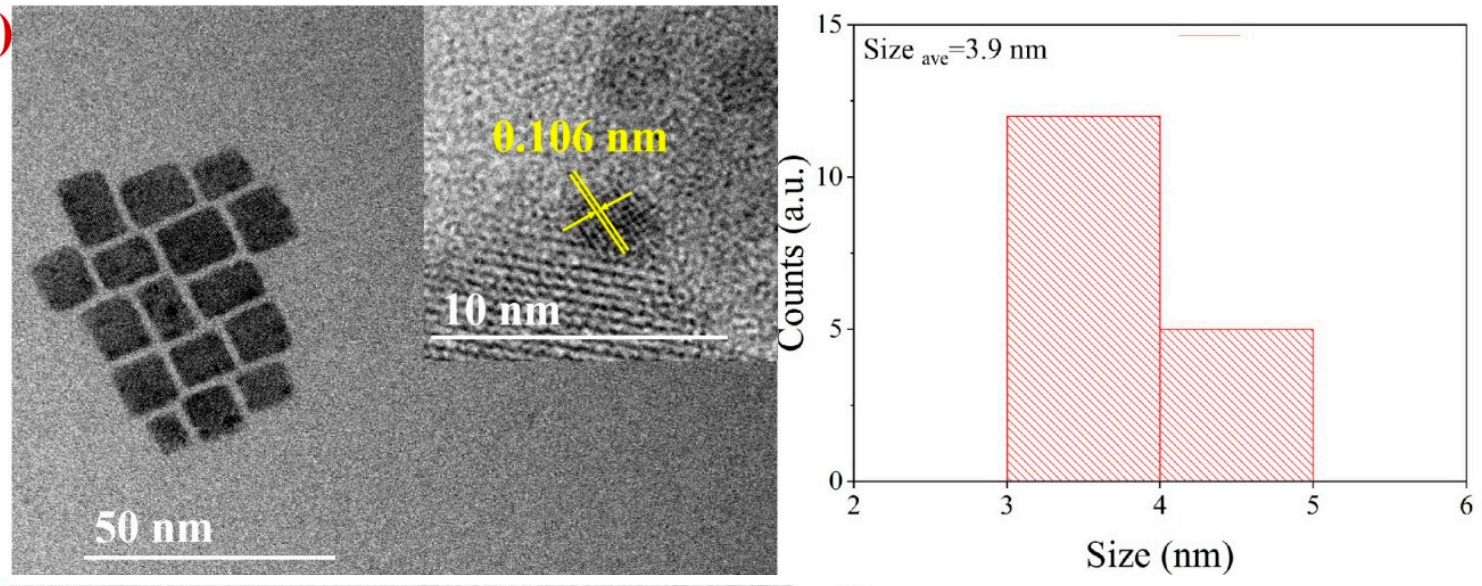

(b)
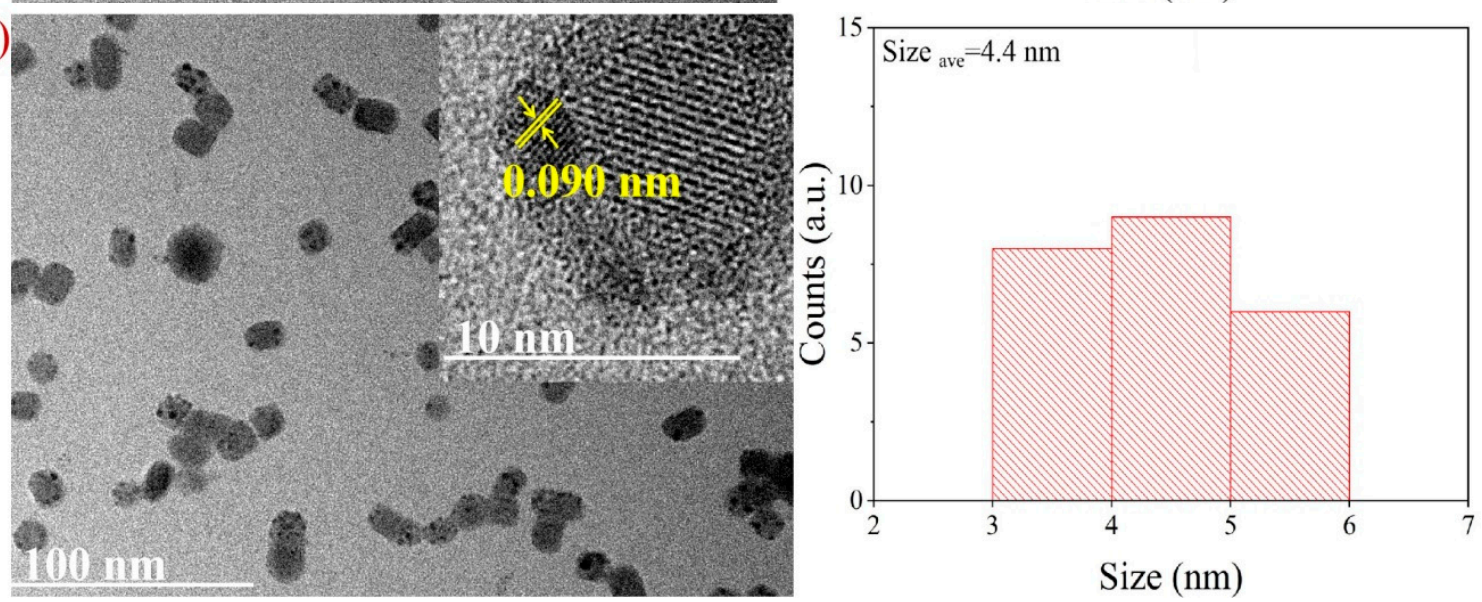

Figure 4. TEM images of (a) $\mathrm{Au} @ \mathrm{CsPbBr}_{3}$ and (b) $\mathrm{Pt} @ \mathrm{CsPbBr} 3$ NCs. 


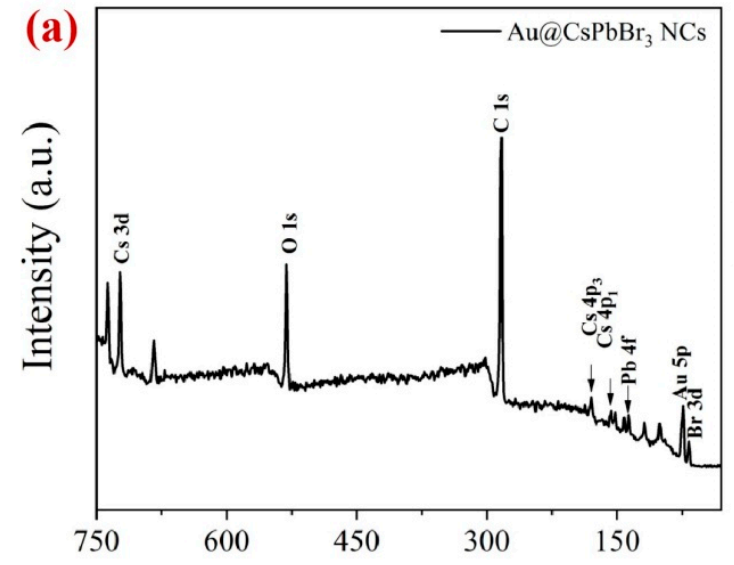

Binding Energy $(\mathrm{eV})$

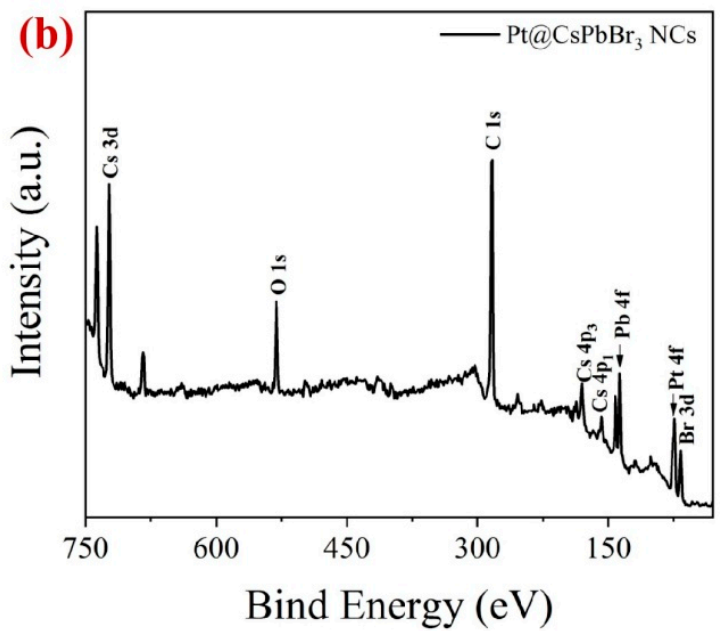

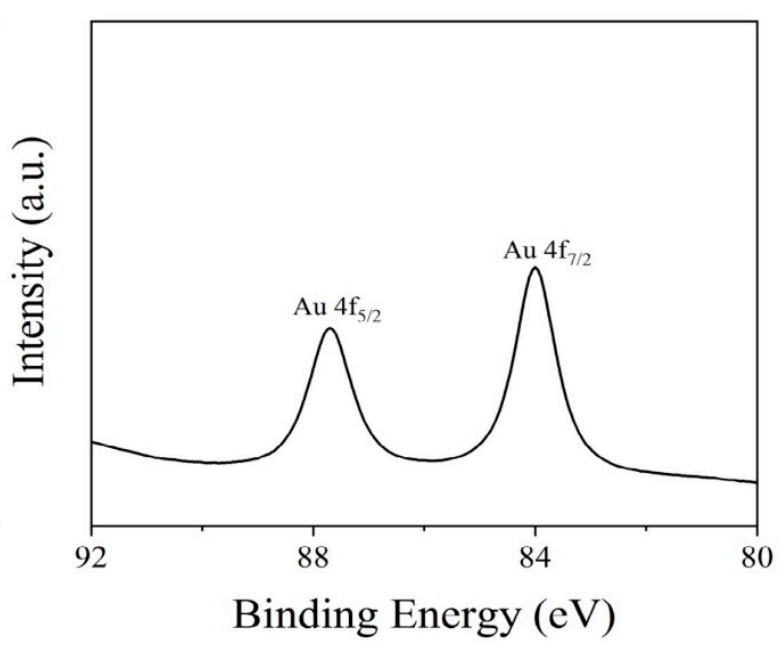

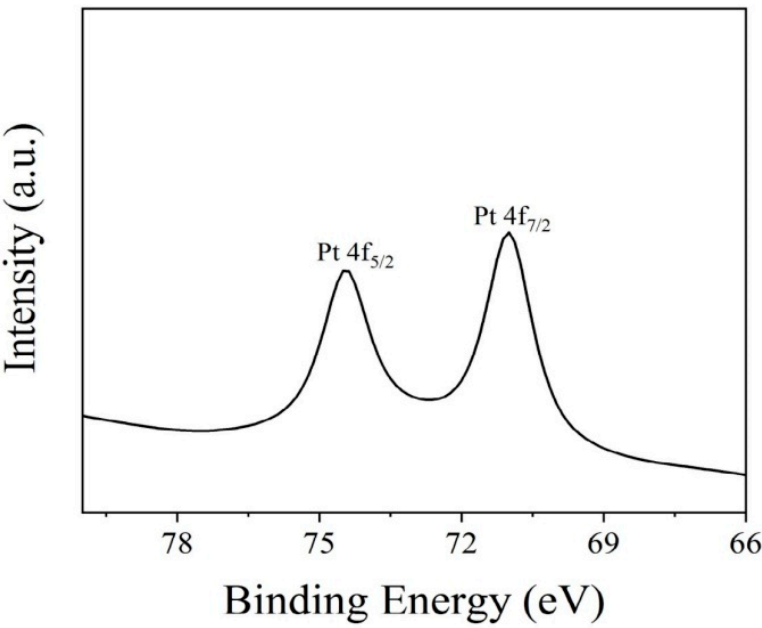

Figure 5. X-ray photoelectron spectroscopy (XPS) data of (a) $\mathrm{Au} @ \mathrm{CsPbBr}$ and (b) $\mathrm{Pt} @ \mathrm{CsPbBr} 3 \mathrm{NCs}_{3}$

Successful deposition of the Au or Pt nanoparticles was also verified through UV-vis absorption measurements. Figure 6a shows the absorption spectra of suspensions containing the different NCs. Compared with the peaks of the pure $\mathrm{CsPbBr}_{3} \mathrm{NCs}$, the absorption edges of the Au@CsPbBr 3 and $\mathrm{Pt} @ \mathrm{CsPbBr} 3$ NCs exhibited a red shift. Furthermore, the Pt@CsPbBr 3 NCs showed enhanced absorption for wavelengths greater than $520 \mathrm{~nm}$, while the $\mathrm{Au} @ \mathrm{Cs} \mathrm{PbBr}_{3} \mathrm{NCs}$ showed additional weak absorption peaks at $420-450 \mathrm{~nm}$. These differences in the absorption spectra may be attributed to the surface plasmonic resonance effect of the deposited noble metal nanoparticles [16]. All the NCs exhibited PL emission peaks at $532 \mathrm{~nm}$, and their full-width-at-half-maximum values were also similar (Figure 6b). A bright-green PL emission was observed under UV-light irradiation (Figure 6c). Timeresolved PL (TRPL) measurements were performed to study charge transfer from the perovskite NCs to the noble metal nanoparticles. The TRPL decay data (Figure 6d) were fitted using a biexponential function of time, $t$, as shown in Equation (1), and the fitted data are listed in Table 1.

$$
I(t)=A_{1} e^{-t / \tau_{1}}+A_{2} e^{-t / \tau_{2}}
$$

where $t$ is the time after optical excitation, $I(t)$ is the luminescence intensity at $t, \tau_{1}$ is the fast transient lifetime related to the charge-trapping process (nonradiative recombination), $\tau_{2}$ is the slow lifetime attributed to the intrinsic band-to-band recombination (radiative recombination) [27], and $A_{1}$ and $A_{2}$ are coefficients corresponding to the contributions of the fast and slow lifetimes, respectively [28]. The $\tau_{2}$ value of the Au or $\mathrm{Pt}_{\mathrm{C}} \mathrm{CsPbBr} \mathrm{Pb}_{3} \mathrm{NCs}$ was much smaller than that of the pure $\mathrm{CsPbBr}_{3} \mathrm{NCs}$ (Table 1). This can be ascribed to the 
quenching of the free charges because of electron transfer from the perovskite to the noble metal nanoparticles.

(a)

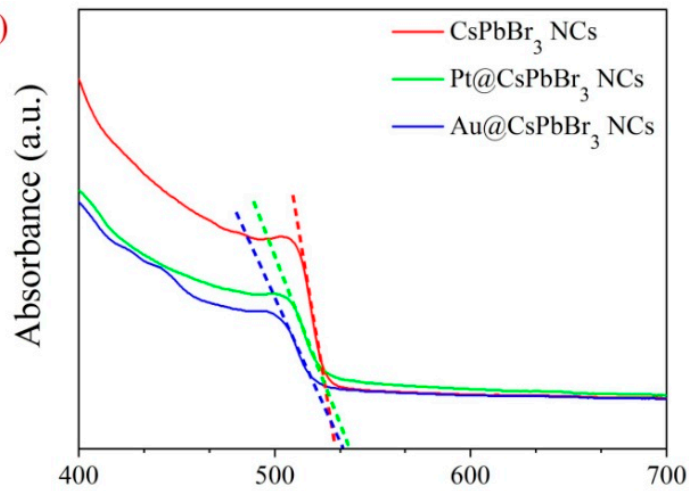

(b)

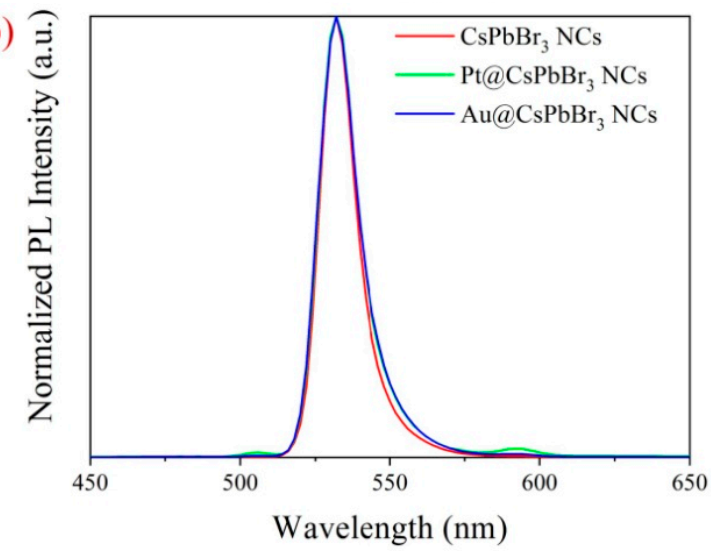

(d)

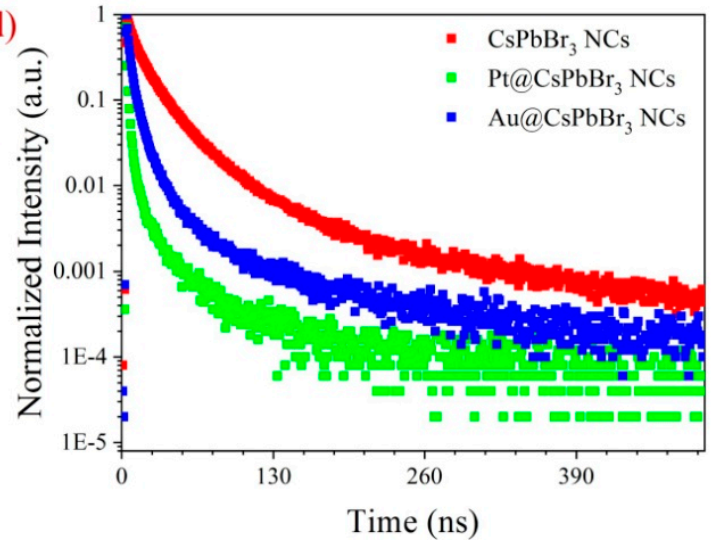

(c)

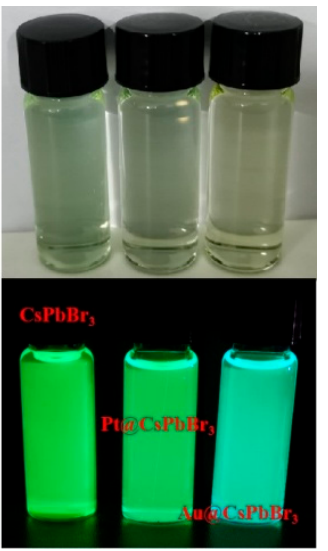

Figure 6. (a) Absorption and (b) photoluminescence (PL) spectra and (c) photographs and (d) timeresolved PL (TRPL) decay curves of different NC suspensions. Photographs were taken under daylight (top) and UV-light illumination (bottom).

Table 1. Fitting parameters for TRPL spectra shown in Figure 6d.

\begin{tabular}{ccccc}
\hline & $\boldsymbol{\tau}_{\mathbf{1}}$ (ns) & $\boldsymbol{A}_{\mathbf{1}}$ & $\boldsymbol{\tau}_{\mathbf{2}}$ (ns) & $\boldsymbol{A}_{\mathbf{2}}$ \\
\hline $\mathrm{CsPbBr}_{3}$ & 14.8 & 0.94 & 59.4 & 0.06 \\
$\mathrm{Au} @ \mathrm{CsPbBr} 3 \mathrm{NCs}$ & 7.03 & 0.95 & 28.2 & 0.05 \\
$\mathrm{Pt} @ \mathrm{CsPbB} \mathrm{PbB}_{3} \mathrm{NCs}$ & 2.49 & 0.96 & 9.97 & 0.04 \\
\hline
\end{tabular}

\section{Materials and Methods}

Materials: Cesium carbonate $\left(\mathrm{Cs}_{2} \mathrm{CO}_{3}, 99.99 \%\right)$, lead (II) bromide $\left(\mathrm{PbBr}_{2}, 99.99 \%\right), \mathrm{OA}$ $(90 \%)$, OAm (80\%), 1-octadecene (ODE, 90\%), and dihydrogen hexachloroplatinate(IV) 
hexahydrate $\left(\mathrm{H}_{2} \mathrm{PtCl}_{6} \cdot 6 \mathrm{H}_{2} \mathrm{O}, \mathrm{AR}\right)$ were purchased from Shanghai Aladdin Biochemical Technology Co., Ltd. (Shanghai, China). Hexane and methanol (99.5\%) were purchased from Sinopharm Chemical Reagent Co., Ltd. (Shanghai, China). Gold(III) chloride trihydrate $\left(\mathrm{HAuCl}_{4} \cdot 3 \mathrm{H}_{2} \mathrm{O}, 99.9 \%\right)$ was obtained from China National Pharmaceutical Group Co., Ltd. (Beijing, China). All chemicals were used without further purification.

Synthesis of $\mathrm{Cs}_{4} \mathrm{PbBr}_{6}$ NCs: The $\mathrm{Cs}_{4} \mathrm{PbBr}_{6} \mathrm{NC}$ s were prepared using the hot-injection method [17]. A cesium oleate solution was prepared by mixing $0.32 \mathrm{~g}$ of $\mathrm{Cs}_{2} \mathrm{CO}_{3}(0.98 \mathrm{mmol})$, $1 \mathrm{~mL}$ of $\mathrm{OA}$, and $16 \mathrm{~mL}$ of ODE in a 100-mL three-neck flask. The solution was dried for $1 \mathrm{~h}$ at $120^{\circ} \mathrm{C}$ under vacuum and then heated in an Ar atmosphere to $150^{\circ} \mathrm{C}$ until all the $\mathrm{Cs}_{2} \mathrm{CO}_{3}$ had reacted with OA. During a typical run to synthesize the $\mathrm{Cs}_{4} \mathrm{PbBr}_{6} \mathrm{NCs}$, OAm $(2 \mathrm{~mL}), \mathrm{OA}(2 \mathrm{~mL}), \mathrm{ODE}(20 \mathrm{~mL})$, and $\mathrm{PbBr}_{2}(0.4 \mathrm{mmol})$ were added to a $100-\mathrm{mL}$ three-neck flask and dried under vacuum for $1 \mathrm{~h}$. The reaction mixture was then heated to $140{ }^{\circ} \mathrm{C}$. Next, $8.8 \mathrm{~mL}$ of a hot cesium oleate solution was rapidly injected into the $\mathrm{PbBr}_{2}$ solution. After $6 \mathrm{~s}$, the reaction mixture was immersed in an ice-water bath for immediate cooling. The product was centrifuged at 12,000 rpm for $5 \mathrm{~min}$ to remove the ODE and unreacted OA as well as the OAm. The precipitate was collected and redispersed in hexane and then centrifuged at $3000 \mathrm{rpm}$ for $5 \mathrm{~min}$ to remove the oversized $\mathrm{Cs}_{4} \mathrm{PbBr}_{6} \mathrm{NCs}$. The concentration of the $\mathrm{Cs}_{4} \mathrm{PbBr}_{6} \mathrm{NC}$ suspension was adjusted to $1 \mathrm{mg} / \mathrm{mL}$ for further synthesis.

Synthesis of $\mathrm{Pt} @ \mathrm{CsPbBr}{ }_{3}$ NCs: During a typical synthesis process, $0.1 \mathrm{~mL}$ of methanol was mixed with $0.4 \mathrm{~mL}$ of an aqueous $\mathrm{H}_{2} \mathrm{PtCl}_{6} \cdot 6 \mathrm{H}_{2} \mathrm{O}$ solution $(1.448 \mathrm{mM})$, and the mixture was injected into $10 \mathrm{~mL}$ of the $\mathrm{Cs}_{4} \mathrm{PbBr}_{6} \mathrm{NC}$ suspension. The system was irradiated with a halogen lamp $\left(\sim 20 \mathrm{~mW} / \mathrm{cm}^{2}\right)$ for $1 \mathrm{~h}$ under vigorous stirring and then kept undisturbed under the ambient conditions for $12 \mathrm{~h}$. The product was centrifuged at $6000 \mathrm{rpm}$ for $5 \mathrm{~min}$. The precipitates were discarded, and the supernatant was collected for characterization.

Synthesis of $\mathrm{Au} @ \mathrm{CsPbBr}_{3}$ NCs: The synthesis procedure was similar to that for $\mathrm{Pt} @ \mathrm{CsPbBr} 3 \mathrm{NCs}$, except that an aqueous $\mathrm{HAuCl}_{4} \cdot 3 \mathrm{H}_{2} \mathrm{O}$ solution $(1.904 \mathrm{mM})$ was used.

Synthesis of $\mathrm{CsPbBr}_{3}$ NCs. The synthesis procedure was similar to that of the $\mathrm{Pt} @ \mathrm{CsPbBr} 3 \mathrm{NCs}$, except that pure water without a metal precursor or methanol was used.

Characterization: The UV-vis absorption spectra were recorded using a Shimadzu UV-vis spectrophotometer (UV3600) (Shimadzu, Kyoto, Japan). The morphologies of the NCs were characterized by means of TEM (JEOL JEM-2100HR) (JEOL Ltd., Tokyo, Japan). For the XRD measurements, the NC suspensions were cast on cleaned glass substrates and dried. The measurements were performed using a Rigaku diffractometer (D/max 2500 PC) (Rigaku Corporation, Akishima, Tokyo, Japan) and $\mathrm{Cu} \mathrm{K} \alpha$ radiation. XPS analysis was carried out using PHI Quantera II (Ulvac-PHI, Kanagawa, Japan). The PL and TRPL decay measurements were performed using a Horiba DeltaFlex PL system (Horiba, Tokyo, Japan) with a 520-nm pulsed laser for excitation at approximately $25^{\circ} \mathrm{C}$.

\section{Conclusions}

In this study, $\mathrm{Au}$ and $\mathrm{Pt} @ \mathrm{CsPbBr} 3 \mathrm{NCs}$ were successfully synthesized via a reaction at the water/hexane interface, which involved the transformation of $\mathrm{Cs}_{4} \mathrm{PbBr}_{6}$ into $\mathrm{CsPbBr}_{3}$ and its subsequent modification with a noble metal. The prepared $\mathrm{CsPbBr}_{3} \mathrm{NCs}$ exhibited a cubic perovskite phase and an average size of approximately $13.5 \mathrm{~nm}$. The deposited $\mathrm{Au}$ and $\mathrm{Pt}$ nanoparticles were crystalline, with an fcc lattice and average diameters of approximately 3.9 and $4.4 \mathrm{~nm}$, respectively. The noble metal modification process affected the charge recombination kinetics of the $\mathrm{CsPbBr}_{3} \mathrm{NCs}$, probably owing to the quenching of the free charges because of electron transfer from the perovskite to the noble metal nanoparticles. This simple strategy for designing and synthesizing perovskite/noble metal nanostructures offers new opportunities to increase their applicability in photodetectors, LEDs, solar cells, photocatalysts, and other such devices. With respect to solar cells, $\mathrm{CsPbBr}_{3}$ NCs modified with a noble metal may be used to construct perovskite quantum dot-based solar cells. Compared with bare perovskite NCs, those modified with a noble metal can enhance the light-harvesting properties of devices owing to their localized surface plasmon resonance effect. In the case of photocatalysts, a composite of $\mathrm{Au}$ or $\mathrm{Pt} @ \mathrm{CsPbBr} 3 \mathrm{NCs}$ and 
reduced graphene oxide or $\mathrm{TiO}_{2}$ would be suitable for use as a visible-light-responsive photocatalyst for $\mathrm{H}_{2}$ evolution in aqueous $\mathrm{HI}$ solutions. Modification with a noble metal has the potential to enhance the photocatalytic activity of $\mathrm{CsPbBr}_{3} \mathrm{NCs}$. Further research in these directions is underway in our laboratory.

Author Contributions: Conceptualization, S.Z. and Z.G.; methodology, S.Z.; validation, L.W., W.L., and M.C.; investigation, J.Z.1; resources, N.Y.; data curation, J.Z.2; writing-original draft preparation, J.Z.1; writing—review and editing, S.Z. and Z.G.; visualization, J.Z.2; supervision, Z.G.; project administration, Z.G.; funding acquisition, S.Z. All authors have read and agreed to the published version of the manuscript.

Funding: This work was partly supported by the National Natural Science Foundation of China (Grant Nos. 51602031 and 51603021), the Qinlan Project (2019), the Natural Science Foundation of the Jiangsu Higher Education Institutions of China (Grant No. 19KJA430014), and the Jiangsu Graduate Scientific Research Innovation Program (2020).

Institutional Review Board Statement: Not applicable.

Informed Consent Statement: Not applicable.

Conflicts of Interest: The authors declare no conflict of interest.

\section{References}

1. Wiley, A.; Dunlap, S.; Zhou, Y.; Nitin, P.; David, B.M. Synthetic Approaches for Halide Perovskite Thin Films. Chem. Rev. 2019, 119, 3193-3295.

2. Zhang, S.; Hu, Z.; Zhang, J.; Jia, X.; Jiang, J.; Chen, Y.; Lin, B.; Jiang, H.; Fang, B.; Yuan, N.; et al. Interface engineering via phthalocyanine decoration of perovskite solar cells with high efficiency and stability. J. Power Sources 2019, 438, 226987. [CrossRef]

3. Zhang, S.; Lu, Y.; Lin, B.; Zhu, Y.; Zhang, K.; Yuan, N.; Ding, J.; Fang, B. PVDF-HFP additive for visible-light-semitransparent perovskite films yielding enhanced photovoltaic performance. Sol. Energy Mater. Sol. Cells 2017, 170, 178-186. [CrossRef]

4. Kojima, A.; Teshima, K.; Shirai, Y.; Miyasaka, T. Organometal Halide Perovskites as Visible-Light Sensitizers for Photovoltaic Cells. J. Am. Chem. Soc. 2009, 131, 6050-6051. [CrossRef]

5. Best Research-Cell Efficiency Chart. Available online: https:/ /www.nrel.gov/pv/cell-efficiency.html (accessed on 13 December 2020).

6. Li, X.; Cao, F.; Yu, D.; Chen, J.; Sun, Z.; Shen, Y.; Zhu, Y.; Wang, L.; Wei, Y.; Wu, Y.; et al. All Inorganic Halide Perovskites Nanosystem: Synthesis, Structural Features, Optical Properties and Optoelectronic Applications. Small 2017, 13, 1603996. [CrossRef]

7. Huang, J.; Lai, M.; Lin, J.; Yang, P. Rich Chemistry in Inorganic Halide Perovskite Nanostructures. Adv. Mater. 2018, 30, 1802856. [CrossRef]

8. Wu, L.; Hu, H.; Xu, Y.; Jiang, S.; Chen, M.; Zhong, Q.; Yang, D.; Liu, Q.; Zhao, Y.; Sun, B.; et al. From Nonluminescent $\mathrm{Cs}_{4} \mathrm{PbX}_{6}(\mathrm{X}=\mathrm{Cl}, \mathrm{Br}, \mathrm{I})$ Nanocrystals to Highly Luminescent $\mathrm{CsPbX}_{3}$ Nanocrystals: Water-Triggered Transformation through a CsX-Stripping Mechanism. Nano Lett. 2017, 17, 5799-5804. [CrossRef]

9. Protesescu, L.; Yakunin, S.; Bodnarchuk, M.I.; Krieg, F.; Caputo, R.; Hendon, C.H.; Yang, R.-X.; Walsh, A.; Kovalenko, M.V. Nanocrystals of Cesium Lead Halide Perovskites $\left(\mathrm{CsPbX}_{3}, \mathrm{X}=\mathrm{Cl}, \mathrm{Br}\right.$, and I): Novel Optoelectronic Materials Showing Bright Emission with Wide Color Gamut. Nano Lett. 2015, 15, 3692-3696. [CrossRef]

10. Zhang, D.; Yu, Y.; Bekenstein, Y.; Wong, A.-B.; Alivisatos, P.; Yang, P. Ultrathin Colloidal Cesium Lead Halide Perovskite Nanowires. J. Am. Chem. Soc. 2016, 138, 13155-13158. [CrossRef]

11. Nedelcu, G.; Protesescu, L.; Yakunin, S.; Bodnarchuk, M.I.; Grotevent, M.J.; Kovalenko, M.V. Fast Anion-Exchange in Highly Luminescent Nanocrystals of Cesium Lead Halide Perovskites ( $\mathrm{CsPbX}_{3}, \mathrm{X}=\mathrm{Cl}, \mathrm{Br}$, I). Nano Lett. 2015, 15, 5635-5640. [CrossRef]

12. Chen, M.; Zou, Y.; Wu, L.; Pan, Q.; Yang, D.; Hu, H.; Tan, Y.; Zhong, Q.; Xu, Y.; Liu, H.; et al. Solvothermal Synthesis of High-Quality All-Inorganic Cesium Lead Halide Perovskite Nanocrystals: From Nanocube to Ultrathin Nanowire. Adv. Funct. Mater. 2017, 27, 1701121. [CrossRef]

13. Tong, Y.; Bladt, E.; Aygüler, M.F.; Manzi, A.; Milowska, K.Z.; Hintermayr, V.A.; Docampo, P.; Bals, S.; Urban, A.S.; Polavarapu, L.; et al. Highly Luminescent Cesium Lead Halide Perovskite Nanocrystals with Tunable Composition and Thickness by Ultrasonication. Angew. Chem. Int. Ed. 2016, 55, 13887-13892. [CrossRef]

14. Dong, Y.; Gu, Y.; Zou, Y.; Song, J.; Xu, L.; Li, J.; Xue, J.; Li, X.; Zeng, H. Improving All-Inorganic Perovskite Photodetectors by Preferred Orientation and Plasmonic Effect. Small 2016, 12, 5622-5632. [CrossRef]

15. Wang, Y.; Chen, Z.; Deschler, F.; Sun, X.; Lu, T.; Wertz, E.A.; Hu, J.; Shi, J. Epitaxial Halide Perovskite Lateral Double Heterostructure. ACS Nano 2017, 11, 3355-3364. [CrossRef]

16. Su, S.; Shen, J.; Sun, H.; Tao, J.; Xu, D.; Wei, T.; Fan, C.; Wang, Z.; Sun, C.; Bi, W. Shape-controlled synthesis of Ag/ $\mathrm{Cs}_{4} \mathrm{PbBr}_{6} \mathrm{Janus}$ nanoparticles. Nanotechnology 2020, 32, 075601. [CrossRef]

17. Hu, H.; Wu, L.; Tan, Y.; Zhong, Q.; Chen, M.; Qiu, Y.; Yang, D.; Sun, B.; Zhang, Q.; Yin, Y. Interfacial Synthesis of Highly Stable $\mathrm{CsPbX}_{3}$ /Oxide Janus Nanoparticles. J. Am. Chem. Soc. 2018, 140, 406-412. [CrossRef] 
18. Balakrishnan, B.K.; Kamat, P.V. Au-CsPbBr 3 Hybrid Architecture: Anchoring Gold Nanoparticles on Cubic Perovskite Nanocrystals. ACS Energy Lett. 2017, 2, 88-93. [CrossRef]

19. Gong, M.; Alamri, M.; Ewing, D.; Sadeghi, S.M.; Wu, J.Z. Localized Surface Plasmon Resonance Enhanced Light Absorption in $\mathrm{AuCu} / \mathrm{CsPbCl} 3$ Core/Shell Nanocrystals. Adv. Mater. 2020, 32, 2002163. [CrossRef]

20. Zhong, Q.-X.; Cao, M.-H.; Hu, H.-C.; Yang, D.; Chen, M.; Li, P.-L.; Wu, L.-Z.; Zhang, Q. One-Pot Synthesis of Highly Stable CsPbBr3@SiO 2 Core-Shell Nanoparticles. ACS Nano 2018, 12, 8579-8587. [CrossRef]

21. Hu, C.; Peng, T.-W.; Hu, X.-X.; Nie, Y.-L.; Zhou, X.-F.; Qu, J.; He, H. Plasmon-Induced Photodegradation of Toxic Pollutants with Ag-AgI $/ \mathrm{Al}_{2} \mathrm{O}_{3}$ under Visible-Light Irradiation. J. Am. Chem. Soc. 2010, 132, 857-862. [CrossRef]

22. Zhang, H.-Y.; Yu, A.-C. Photophysics and Photocatalysis of Carbon Nitride Synthesized at Different Temperatures. J. Am. Chem. Soc. 2017, 139, 5216-5224. [CrossRef]

23. Zhu, M.; Chen, P.; Liu, M. Graphene Oxide Enwrapped Ag/AgX (X = Br, Cl) Nanocomposite as a Highly Efficient Visible-Light Plasmonic Photocatalyst. ACS Nano 2011, 5, 4529-4536. [CrossRef] [PubMed]

24. Saidaminov, M.I.; Almutlaq, J.; Sarmah, S.; Dursun, I.; Zhumekenov, A.A.; Begum, R.; Pan, J.; Cho, N.; Mohammed, O.F.; BakrPure, O.M. Pure $\mathrm{Cs}_{4} \mathrm{PbBr}_{6}$ : Highly Luminescent Zero-Dimensional Perovskite Solids. ACS Energy Lett. 2016, 1, 840-845. [CrossRef]

25. Rakočević, L.; Štrbac, S.; Srejić, I. Hydrogen evolution on Au/GC and PdAu/GC nanostructures in acid solution: AFM, XPS, and electrochemical study. Int. J. Hydrogen Energy 2021. [CrossRef]

26. Zhang, X.; Huang, Q.; Li, Z.; Ma, A.; He, X.; Lin, S. Effects of silicotungstic acid on the physical stability and electrocatalytic activity of platinum nanoparticles assembled on graphene. Mater. Res. Bull. 2014, 60, 57-63. [CrossRef]

27. Yang, S.; Dai, J.; Yu, Z.; Shao, Y.; Zhou, Y.; Xiao, X.; Zeng, X.; Huang, J. Tailoring Passivation Molecular Structures for Extremely Small Open-Circuit Voltage Loss in Perovskite Solar Cells. J. Am. Chem. Soc. 2019, 141, 5781-5787. [CrossRef]

28. Wu, Y.; Wang, P.; Wang, Z.; Cai, B.; Zheng, X.; Chen, Y.; Yuan, N.; Ding, J.; Zhang, W. Heterojunction Engineering for High Efficiency Cesium Formamidinium Double-Cation Lead Halide Perovskite Solar Cells. ChemSusChem 2018, 11, 808. [CrossRef] 